\title{
Attitude of married women towards contraceptive use in Ilorin Metropolis, Kwara State, Nigeria
}

\author{
Lateef Omotosho Adegboyega
}

University of Ilorin - Counsellor Education Ilorin, Kwara, Nigeria.

\begin{abstract}
Background: Contraceptive use helps in preventing unplanned pregnancy and reducing maternal death among married women. Objective: To investigate the attitude of married women towards contraceptive use in Ilorin metropolis, Kwara State. The study also examined whether the variables of age and educational attainment would influence attitude of married women towards contraceptive use in Ilorin metropolis.

Methods: Descriptive survey design and analytical methods were adopted for the study. Simple random sampling technique was adopted to draw a total of 200 respondents. A questionnaire was used to collect data for the study. Mean and rank order was used to answer the research question while Analysis of Variance was used to test the hypotheses at 0.05 alpha level.

Results: The attitude of married women towards contraceptive use in Ilorin metropolis was negative. There was no significant difference in the attitude of married women towards contraceptive use based on age and educational attainment.

Conclusion: Most married women in Ilorin metropolis have negative attitude towards contraceptive use. We recommended that counselling services be provided to women on how to deal with side effects associated with various modern contraceptive methods.
\end{abstract}

Keywords: Attitude, married women, contraceptive use.

DOI: https://dx.doi.org/10.4314/ahs.v19i2.10

Cite as: Adegboyega LO. Attitude of married women towards contraceptive use in Ilorin Metropolis, Kwara State. Afri Health Sci.2019;19(2): 1875-1880. bttps://dx.doi.org/10.4314/abs.v19i2.10

\section{Introduction}

Contraceptive is derived from Latin word "kon-truh-septiv" meaning tending or serving to prevent conception or impregnation. It can also be described as a device or drug serving to prevent pregnancy. According to Darroch $^{1}$, contraceptive use helps couples and individuals realize their basic right to decide freely and responsibly, when and how many children to have. The growing use of contraceptive methods has resulted in not only improvements in health-related outcomes such as reduced maternal mortality and infant mortality ${ }^{2}$.

Many developing economies are characterized by rapid population growth that is partly attributed to high fertility

\section{Corresponding author: \\ Lateef Omotosho Adegboyega, \\ University of Ilorin - Counsellor Education \\ Ilorin, Kwar, Nigeria. \\ Email: adegboyega.lo@unilorin.edu.ng}

rate, high birth rates accompanied by steady declines in death rates, low contraceptive prevalence rate and high

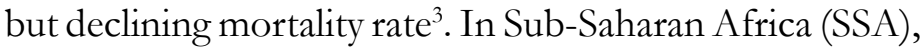
the rate ofpopulation growth is one of the highest in the world (2.8 percent) compared to the rest of the world4. Nigeria being the most populous country in Africa and seventh most populous country in the world with an estimation of 183 million people living in the country, which is projected to reach 285 million by 2050, there are estimated 35 million women of reproductive age in the country, with an annual number of births of approximately 7 million and annual population growth of $3.2 \%$ per annum ${ }^{4}$.

Family planning services are educational and comprehensive medical or social activities which enable individuals and couples to determine freely the number and spacing of their children. Generally, contraceptive usage awareness and knowledge in Nigeria is high among women of reproductive age in Nigeria, despite this high contraceptive awareness and knowledge, studies have also shown

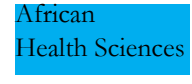

(C) 2019 Adegboyega LO. Licensee African Health Sciences. This is an Open Access article distributed under the terms of the Creative commons Attribution License (https://creativecommons.org/licenses/BY/4.0), which permits unrestricted use, distribution, and reproduction in any medium, provided the original work is properly cited. 
disappointingly very low usage of contraception in Nigeria, this fact was further buttressed by 2013 Nigeria demographic and health survey (NDHS) report which placed modern contraceptive usage in Nigeria at 10\%, amounting as a $6 \%$ increase over a 24 year period ${ }^{5}$. However, despite the increase in supply of and demand for family planning services, gross inequities exist both between and within countries in the use of contraceptives, posing challenges to health policy and programming. The contraceptive use rate is low among the younger people, some of the younger people may not use contraceptive although they are not prepared to take child, among them who faced unplanned pregnancy, and some of the younger women may take illegal abortion5. About $27 \%$ married adolescent in Bangladesh are faced with unplanned birth5.

Contraceptive usage helps in controlling the population of a particular country in order to reduce poverty or any form of mismanagement in the country. Contraceptive prevalence rates have correlated with maternal mortality and it has been shown that countries with low contraceptive prevalence rates are also countries with highest maternal mortality ratios. The most commonly cited reason for no nurse given by women with unintended pregnancies in a government survey was "I didn't think I could get pregnant"6. In a nationally representative survey of unmarried young adults aged 18-29, 44 percent of young women agree or strongly agreed with the statement, "It doesn't matter whether you use birth control or not; when it is your time to get pregnant it will happen" 7 .

Moreover, when they are using contraception, many people do not use the most effective methods. Among sexually active women aged 20-24, about 3 percent use intrauterine devices (IUDs) as their primary form of contraception, 27 percent use the Pill, 7 percent use another hormonal method (e.g. patch, injectable, or contraceptive ring), and 15 percent rely on condoms (Jones, Mosher, \& Daniels, 2012). Long-acting reversible contraception (LARCs), which include implants and IUDs, have very low failure rates $(1 \%)$, lower by far than the two most commonly used forms of contraception, condoms (18\%) and the Pill $(9 \%)^{8}$. Current living children and women's skilled occupation were associated with the contraceptive choice of both younger and older women, current living children and women occupation are playing vital role in contraceptive use in Bangladesh ${ }^{8}$.

Nigeria has one of the highest maternal mortality ratios in sub-Saharan Africa, and ranks as the country with the second highest number of maternal deaths in the world 9 Contraceptive usage reduced unintended pregnancy, and induced abortion which are detrimental to women's health ${ }^{10}$. Family planning is closely related to women health status because it ensures a healthy reproductive life and keep away from unsafe abortions, miscarriages, and stillbirths, unwanted pregnancy and the risks of giving birth. Children whose conception was unintended are more likely to have poor physical or mental health and are more likely to engage in delinquent behaviour during adolescence, even controlling for family characteristics10. While much of the research has been correlation in nature, some studies have investigated the causal relationship between unmarried or unintended births and maternal outcomes. For example, women have benefited significantly from legal and technological advances that have given them more control over the timing of their families. Studies of the historical expansion of oral contraception have used exogenous variation in state laws governing the sale of birth control to make the causal claim that increased access to the pill raised college attendance and graduation rates ${ }^{7}$.

The proportion of Nigerian women using modern contraceptive methods rose from 3\% in 1990 to $8 \%$ in $2003^{11}$. Recently, in developing countries, it has been increasing to keep family size small and intention for using appropriate family planning methods ${ }^{1}$. Contraceptive use is the most important factor that controls the fertility level in modern societies. About 50\% married women use contraceptive all over the world and the rate is high, about $70-80 \%$ among the developed countries ${ }^{5}$.

Knowledge about contraceptives and their side effects may affect their actual use indirectly, through its effect on the attitudes people have regarding contraceptive use ${ }^{7}$. Nigerian women with positive attitudes towards contraception (i.e. those who approved family planning and those who discouraged early marriages) were found to use contraceptives more than other women. Thus, the need to investigate the attitude of married women towards contraceptive use in Ilorin, Kwara State.

\section{Problem}

Unintended pregnancy has been a major menace that affects women which may likely lead to abortion, abortion sometimes lead to death, distort some internal organ which might lead to terminal illness or affects the womb ${ }^{12}$. While family planning impacts all the Millennium De- 
velopment Goals (MDGs), it is most directly associated with MDGs, improving maternal health. Contraceptive use reduces the pregnancy rate, the number of unplanned pregnancy and associated induced abortions and the proportion of high risk pregnancies, therefore causing a reduction in maternal mortality and an improvement in maternal and child health. Oyedokun ${ }^{3}$ asserted that it has been estimated that in Nigeria a reduction in fertility by 1 child per women would lead to a $13 \%$ increase in Gross Domestic production per capital within 20 years.

\section{Methods}

\section{Research design}

Descriptive survey research design and analytical methods were used for the study.

\section{Participants and Setting}

The population for this study comprises married women in Ilorin metropolis. Ilorin metropolis is made up of three (3) local governments which are; Ilorin East, Ilorin West, and Ilorin south Local Government Areas. Total samples of two hundred (200) respondents were selected for this study using simple random sampling technique. The age range of the respondents was in three age brackets viz: 25-39 years; 40-49 years and 50 years and above.

\section{Instrumentation}

The main instrument used for this study was a researcher-developed questionnaire, entitled Attitude of Married Women Towards Contraceptive Use Questionnaire" (AMWTCUQ). The instrument comprised two sections. Section A consists of personal data of the respondents. Section B contains 20 items which sought to find out the attitude of married women towards contraceptive use.
The instrument (questionnaire) was validated by experts in counselling while the reliability of the questionnaire was determined through test re-test method. The set of scores were subjected to Pearson's Product Moment Correlation (PPMC) and a reliability co-efficient of 0.76 was obtained, indicating that the instrument is reliable for use.

\section{Ethical issues}

The purpose of the study was clearly explained to the respondents by attaching informed consent forms to the instrument. Respondents consent was sought to include them in the study and they were informed that participation in the study was voluntary and that they could opt out at any point in time. Respondents were assured anonymity and confidentiality of any information provided on the questionnaire form. Each participant's identity was protected.

\section{Data analysis}

Percentage, statistical means, standard deviation, and Analysis of Variance (ANOVA) were used to analyze the data collected. A P value of less than 0.05 was takenassignificant.

\section{Results}

\section{Attitude of married women to contraceptive use is shown in Table 1.}

Responses to items that sought information on attitude of married towards contraceptive as expressed by married women in Ilorin metropolis, Kwara State revealed that the attitude of married towards contraceptive in Ilorin metropolis, Kwara State was negative, because the benchmark weighted mean score stood at 50 and their weighted mean score was 49.42 which is below the benchmark weighted mean score. 
Table 1: Cumulative mean of attitude of married towards contraceptive as expressed by married women in Ilorin Metropolis, Kwara state

\begin{tabular}{lll}
\hline S/N & Attitude of Married towards Contraceptive & Mean \\
\hline $\mathbf{1 .}$ & I encourage its use by my fellow married women & $\mathbf{2 . 4 7}$ \\
$\mathbf{2 .}$ & I use contraceptive because it influences effective family planning & $\mathbf{2 . 6 8}$ \\
$\mathbf{3 .}$ & I consider contraceptive to be good for an enhanced fertility level & $\mathbf{2 . 2 0}$ \\
$\mathbf{4 .}$ & I use contraceptive to enhance birth weight & $\mathbf{2 . 7 0}$ \\
$\mathbf{5 .}$ & I do consider its use so as to reduce infant mortality & $\mathbf{2 . 1 5}$ \\
$\mathbf{6 .}$ & I consider its use because birth control is relevant & $\mathbf{2 . 4 7}$ \\
$\mathbf{7 .}$ & I do not only use contraceptives when breast feeding babies & $\mathbf{3 . 0 3}$ \\
$\mathbf{8 .}$ & I consider contraceptive as less complicated & $\mathbf{2 . 2 9}$ \\
$\mathbf{9 .}$ & I consider contraceptives to be a very effective method & $\mathbf{2 . 0 8}$ \\
$\mathbf{1 0}$ & I do use contraceptive to enhance healthy lifestyle & $\mathbf{1 . 8 6}$ \\
$\mathbf{1 1}$. & I do use contraceptives because they are affordable and relatively cheap & $\mathbf{2 . 9 1}$ \\
$\mathbf{1 2 .}$ & I feel relaxed when using it because it is safer & $\mathbf{2 . 7 3}$ \\
$\mathbf{1 3 .}$ & I feel comfortable when using it & $\mathbf{2 . 4 1}$ \\
$\mathbf{1 4}$. & I do not often approve of it & $\mathbf{2 . 5 9}$ \\
$\mathbf{1 5}$. & I do use contraceptive for pleasurable sex with my partner & $\mathbf{2 . 5 1}$ \\
$\mathbf{1 6}$ & I do use contraceptive to avoid unplanned pregnancy & $\mathbf{2 . 0 4}$ \\
$\mathbf{1 7}$. & I do use contraceptive because my husband approve of it & $\mathbf{1 . 8 8}$ \\
$\mathbf{1 8}$ & I carefully read the instruction before use & $\mathbf{2 . 1 5}$ \\
$\mathbf{1 9}$ & I am not afraid of contraceptive use & $\mathbf{3 . 0 0}$ \\
$\mathbf{2 0}$ & I have adequate knowledge & $\mathbf{3 . 3 4}$ \\
\hline & Weighted Mean Score & $\mathbf{4 9 . 4 2}$
\end{tabular}

\section{Hypotheses}

Hypothesis one: There is no significant difference in the attitude of married women towards contraceptive use as expressed by married women in Ilorin metropolis, Kwara State based on age.
Table 2 shows a cal. F-value of 2.194 with calculated p-value of 0.114 at 0.05 alpha level. Since the calculated p-value of 0.114 is greater than 0.05 alpha level, hypothesis one is thus not rejected.

Table 2: ANOVA: Summary of attitude of married women towards contraceptive use as expressed by married women in Ilorin Metropolis, Kwara State, based on age

\begin{tabular}{lllllll}
\hline Source & Sum of Squares & df & Mean Squares & F & Sig. & Decision \\
\hline Between Groups & 666.150 & 2 & 333.075 & & & $\mathbf{H}_{01}$ \\
Within Groups & 29910.405 & 197 & 151.829 & 2.194 & 0.114 & $\begin{array}{l}\text { Not } \\
\text { Rejected }\end{array}$ \\
Total & $\mathbf{3 0 5 7 6 . 5 5 5}$ & $\mathbf{1 9 9}$ & & & & \\
\hline
\end{tabular}


Hypothesis Two: There is no significant difference in the attitude of married women towards contraceptive use as expressed by married women in Ilorin metropolis, Kwara State based on highest educational attainment.
Table 3 shows a cal. F-value of 0.721 with calculated p-value of 0.541 at 0.05 alpha level. Since the calculated p-value of 0.541 is greater than 0.05 alpha level, hypothesis three is thus not rejected.

Table 3: ANOVA Summary of attitude of married women towards contraceptive as expressed by married women in Ilorin Metropolis, Kwara State, based on highest educational attainment

\begin{tabular}{lllllll}
\hline Source & Sum of Squares & df & Mean Squares & F & Sig. & Decision \\
\hline Between Groups & 333.729 & 2 & 111.243 & & & $\mathbf{H}_{\mathbf{0 3}}$ \\
Within Groups & 30242.826 & 197 & 154.300 & 0.721 & 0.541 & Not Rejected \\
Total & $\mathbf{3 0 5 7 6 . 5 5 5}$ & $\mathbf{1 9 9}$ & & & & \\
\hline
\end{tabular}

\section{Discussion}

The findings of this study revealed that the attitude of married women towards contraceptive as expressed by married women in Ilorin metropolis, Kwara State was negative. This finding negates that of Agarwal, Samanta, Bhusan and Anant ${ }^{13}$ who reported that attitude and practice of contraception among patients in a semi-urban tertiary hospital was positive.

Hypothesis one revealed that there was no significant difference in the attitude of married women towards contraceptive in Ilorin metropolis, Kwara State based on age. This finding is in supports of that of Lwelamira, Mnyamagola and $\mathrm{Msaki}^{14}$ who reported that knowledge, attitude and Practice (KAP) towards modern contraceptives among married women of reproductive age in Mpwapwa District, Central Tanzania differs based on age.

Hypothesis two also shows that there was no significant difference in the attitude of married women towards contraceptive in Ilorin metropolis, Kwara State based on highest educational attainment. This finding is in dissonance with that of Tilahun, Coene, Luchters, Kassahun, Leye, et. $\mathrm{al}^{15}$ which found that there was no significant difference in the attitude of married women towards contraceptive as expressed by married women in Jimma Zone, Ethiopia based on level of education.

\section{Conclusion}

The findings of this study revealed that the attitude of married women towards contraceptive in Ilorin Metropolis, Kwara State was negative. Also, findings revealed that there were no significant differences in the attitude of married women towards contraceptive as expressed by married women based on age and highest educational attainment.

\section{Recommendations}

Based on findings of this study, it is recommended that: - Education of the community on importance of having smaller families should be intensified.

- Campaigns to raise awareness on importance of modern contraceptives among males (husbands) should be emphasized and should go along with those involving women. This could be through involvement of males in family planning programs.

- More education/counselling services to women on how to handle/deal with side effects associated with various modern contraceptives methods should be given due weight and campaigns against myths and misbeliefs that negatively affect use of modern contraceptive in the study population should be initiated.

\section{Conflict of interest}

None declared.

\section{References}

1. Darroch JE Sedgh, G. \& Ball, H. (2011). Contraceptive technologies: Responding to women's needs. New York: Guttmacher Institute.

2. Campbell M, Hodoglugil N, Potts M. Barriers to fertility regulation: A review of the literature. Stud Fam Plan. 2006;32:87-98.

3. Oyedokun, A. O. (2007). Determinants of contraceptive usage: Lesson from women in Osun State, Nigeria. Journal of Humanities and Social Science.

4. United Nations Department of Economic and Social Affairs (UNDESA). (2008). World contraceptive use 
2007.” New York: United Nations, .2009. World Population Prospects: The 2008 Revision. New York: United Nations.

5. Greanga, A.A.D. Gillespie, S. Karklins, A.O. \& Tsui, O.(2011). Low use of contraceptive among poor women in Africa.

6. Mosher, W. D., \& Jones, J. (2010). Use of contraception in the United States: 1982-2008 (23). Retrieved from http://www.cdc.gov/nchs/data/series/sr_23/sr23_029. pdf.

7. Sawhill I, Thomas A, Monea E (2010). An ounce of prevention: Policy prescriptions for reducing the prevalence of fragile families. The Future of Children, 20, 133155.

8. Trusell, J. (2011). Contraceptive failure in the United States. Contraception, 83(5), 397-404.

9. World health organization (WHO). (2005). Maternal mortality ratio in 2005: Estimates by UNICEF, WHO, UNFPA. World Bank. Geneva. WHO

10. Hossain, M. (2005). Analysing the relationship between family planning workers' contact and contraceptive switching in rural Bangladesh using multilevel modeling. J. biosoc. Sci.
11. National Population Commission (NPC) [Nigeria] and ORC Macro. (2004). Nigeria Demographic and Health Survey 2003. Calverton, Maryland: National Population Commission and ORC Macro.

12. Ashraf, Q. H., Weil, D. N., \& Wilde, J. (2013). The effect of fertility reduction on economic growth. Population and Development Review, 39(1), 97-130. http://doi. org/10.1111/j.1728-4457.2013.00575.x

13. Agarwal, M., Samanta, S., Bhusan, D. \& Anant, M. (2017). Assessing knowledge, attitude, and practice of contraception: A cross- sectional study among patients in a semi- urban tertiary hospital. International Journal of Reproduction, Contraception, Obstetrics and Gynecology, 6(2), 720-724.

14. Lwelamira, J. Mnyamagola, G. \& Msaki, M. M. (2012). Knowledge, Attitude and Practice (KAP) towards modern contraceptives among married women of reproductive age in Mpwapwa District, Central Tanzania. Current Research Journal of Social Sciences, 4(3), 235-245.

15. Tilahun T, Coene G, Luchters S, Kassahun W. \& Leye, E. (2013). Family planning knowledge, attitude and practice among married couples in Jimma Zone, Ethiopia. PLoSOne 8(4), e61335. doi:10.1371/journal. pone.0061335. 